Bangladesh Journal of Anatomy January 2009, Vol. 7 No. 1 pp. 22-25

\title{
Percentage Area of Intimal Surface of the Infra-Renal Segment of Abdominal Aorta Affected by Atherosclerosis - A Postmortem Study
}

\author{
Saifun Naher ${ }^{1}$, Humaira Naushaba ${ }^{2}$, Jesmin Ara Begum ${ }^{3}$, Naznin Akhter ${ }^{4}$
}

\begin{abstract}
:
Context: Atherosclerosis and its complications are still the major source of morbidity and mortality in the industrial world, and estimates have been offered that at its present rate of growth, will be the major cause of death from this disease by the year 2020 in the entire world, (Joseph 2004). The seemingly increased incidence of atherosclerotic disorders in the country, their fatal consequences and the paucity of relevant data, the present study was carried out to assess the percentage of area involved in atherosclerotic lesion of abdominal aorta of Bangladeshi males.
\end{abstract}

Study design: Descriptive cross-sectional.

Place \& time of study: In the department of Anatomy, Sir Salimullah Medical College, Dhaka, during the study period of July 2005 to June 2006.

Method: Abdominal aorta were collected from fifty Bangladeshi male dead bodies who underwent routine postmortem examination due to accidental death. Sudy was done to find out the macroscopic extent of atherosclerotic lesion of abdominal aorta (below the origin of renal arteries) from Bangladeshi male of different ages. The subjects were divided into lower (8-29), middle (30-40), higher (42-92) age groups. The atherosclerotic lesions were stained red by treating the aorta with sudden IV. The percentage of area on the intimal surface showing atherosclerotic lesion were measured by AutoCAD.

Result: The percentage of area involved in atherosclerotic lesion was increase with advancing age. Unpaired student ' $t$ ' test for statistical analysis revealed significant difference. $(P<0.01)$ in between lower \& higher age groups.

Key words: Abdominal aorta, Atherosclerosis

Introduction:

Atherosclerosis is the most frequent and important intimal disease of large and medium sized arteries. It is characterized by deposition of cholesterol and cholesterol esters which are phagocytosed by macrophages (monocytes) that migrates through endothelial layer, take up lipid and become foam cells ${ }^{1}$. The name atherosclerosis is derived from

1. Associate Professor \& Head, Department of Anatomy, Holy Family Red Crescent Medical College Hospital

2. Professor \& Head, Department of Anatomy, Sir Salimullah Medical College \& Mitford Hospital, Dhaka

3. Associate Professor, Department of Physiology, Ibrahim Medical College

4. Associate Professor, Department of Physiology, Holy Family Red Crescent Medical College Hospital

Correspondence: Saifun Naher
Greek word "sclerosis" means hardening refers to thickening of arterial intima and "athera" means gruel or porridge refers to accumulation of lipid².

The overall nature of the progress of the atherosclerosis is age dependent. It begins in childhood and progresses with advancing age $\mathrm{e}^{3}$. It is claimed that atherosclerosis exists even in foetal life and evolves slowly over decades, impacted by a myriad of environmental and genetic factors ${ }^{4}$.

Atherosclerosis and its complications are still the major source of morbidity and mortality in the industrialized world and much of $\mathrm{Asia}^{5}$ and estimates have been offered that at its present rate of growth, it will be the major cause of death by the year 2020 in the entire world ${ }^{4}$. 
In the aorta, the atherosclerotic lesion appear as fatty streaks as early as in the infancy. It occurs in the aorta of all children irrespective of race, sex or environment by age $10^{2}$. By age 35 years, this lesion have been found to occupy $30-50 \%$ of the aortic surface area ${ }^{6}$.In abdominal aorta, atherosclerosis is more common in the segment below the origin of the renal arteries, called infra-renal segment ${ }^{7,8}$. The changes of atherosclerosis initially involve the intimal layer of the arterial wall in which there is focal accumulation of a variety of complex lipids, proteins and carbohydrates, cellular components, such as smooth muscle cells and macrophage like cells, blood and blood constituents and in more advanced lesion, high concentrations of mineral, particularly calcium ${ }^{9}$.

In the developing countries like ours, atherosclerosis and its complications seem to be on the rise. The problem has been aggravated by paucity of the information on the atherosclerotic status of the people of Bangladesh. As study of atherosclerosis in the living population is difficult in many ways including its cost-effectiveness, postmortem studies have been regarded as one good way of dealing with the problem.

The abdominal aorta is involved earliest by atherosclerotic lesions and more common in the segment below the origin of the renal arteries, called infra-renal segment. Males are more sufferer from atherosclerosis related disease. It was of much interest to assess the parentage of intimal area affected by atherosclerotic lesion in the infra-renal segment of abdominal aorta of 50 unclaimed cadavers of Bangladeshi males.

\section{Materials \& Methods:}

The study was carried out in the Department of Anatomy, Sir Salimullah Medical College, Dhaka during the period of July 2005 to June 2006. Fifty (50) abdominal aortae were collected from unclaimed male dead bodies autopsied within 48 hours after death to avoid decomposition of the tissue. Collected samples were washed thoroughly in tap water and squeezed gently to remove blood clots from the lumina of the blood vessels as far as possible. Intimal surface of the selected portion of each of the aorta taken for macroscopic study was opened by a longitudinal incision through middle of the anterior wall then it was flattened by sandwiching it between two sized matched glass slabs kept together by rubber bands (Fig.-1). After routine preparation, each aortic segment was stained with sudden IV solution ${ }^{10}$. Sudden IV colored the fatty lesions of intima red. For taking macroscopic measurement of the atherosclerotic lesions a transparent plastic sheet was placed on the aortic sample. Then the sheet was fixed on the waxed tray putting pins close to the four corners of the sample. The complete outline of the arterial wall was then traced with a black OHP marker pen (Artline $853 \mathrm{~F}$, Permanent). During outlining the arteries and their lesions, the marker pen was so placed that the outer margin of the outline produced by it was coincided with margins of the arteries and lesions respectively. Then different types of atherosclerotic lesions e.g. fatty streaks, fibrous plaque, calcification were outlined differently with different colour marker pen (853 F, Permanent) on

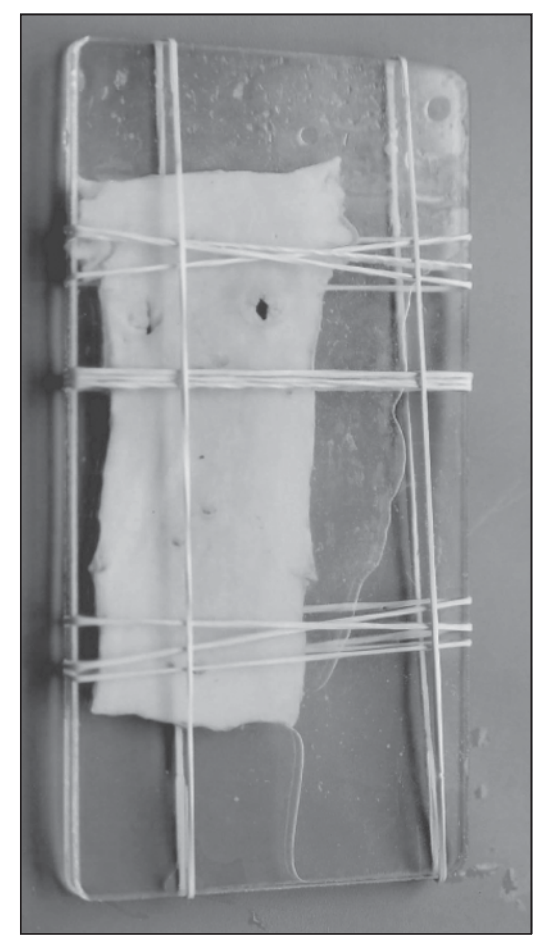

Fig.-1: Photomicrograph showing the aorta was flattened by sandwiching it between two sizematched (length $18 \mathrm{~cm} \&$ width $8 \mathrm{~cm}$ ) glass slabs kept together by rubber bands. 
the transparent sheet. Thus the total atherosclerotic lesion as well as different types of lesion was measured separately. Then the tracing was ready for computer measurement of the total surface area of atherosclerotic lesion on the intimal surface. An identical number was put on the traced outline on the transparent sheet. The traced outlines on the transparent sheets was then scanned into computer Microsoft Photo-Editor Program. The scanned tracings was then transferred to the AutoCAD (Computer Aided Design) Software for measuring the areas covered by the tracing for total area as well as area of different types of atherosclerotic lesions. Measurements was expressed in square millimeters $\left(\mathrm{mm}^{2}\right)$.

\section{Results:}

There was a general trend of increasing area involvement by atherosclerotic lesion with advancing age. Atherosclerotic lesions were observed in all the aortae of three age groups in the present study. The study revealed a trend of increas in the mean percentage of intimal surface area of infra-renal segment of abdominal aorta affected by atherosclerosis with advancing age. A significant difference $(P<0.01)$ in the mean percentage area affected by atherosclerotic lesion was observed between lower and higher age groups. No significant differences were found between middle age group with lower and higher age groups of the aortae. The percentage of affected area in lower part was found to be positively correlated with age-at-death( $r$ $=0.440, \mathrm{P}<0.001$ ) shown in Tavke-1 \& Figure: 2 .

Table-I

Percentage area of intimal surface affected by atherosclerosis in the infra-renal segment (lower part) of the aorta.

\begin{tabular}{lccc}
\hline Age group (years) & Number of aortae & \multicolumn{2}{c}{ Percentage of affected area } \\
& & Range & Mean \pm SD \\
\hline Lower (8-29) & 26 & $0.38-100.00$ & $28.69 \pm 28.24$ \\
Middle(30-40) & 10 & $0.92-92.64$ & $41.35 \pm 31.39$ \\
Higher(42-92) & 15 & $11.34-100.00$ & $61.38 \pm 31.55$ \\
\hline
\end{tabular}

' $p$ ' valuesLower age vs Middle age $>0.10^{\text {ns }}$ Lower age vs Higher age $>0.01$ ** Middle age vs Higher age $>0.10^{\text {ns }}$ Statistical analysis done by unpaired student's ' $\mathrm{t}$ ' test, ns=not significant, ${ }^{*}=$ significant.

Ï\% Infra-renal segment(lower part): extends from lower margin of the origin of right \& left renal arteries to the margin of the bifurcation of abdominal aorta.

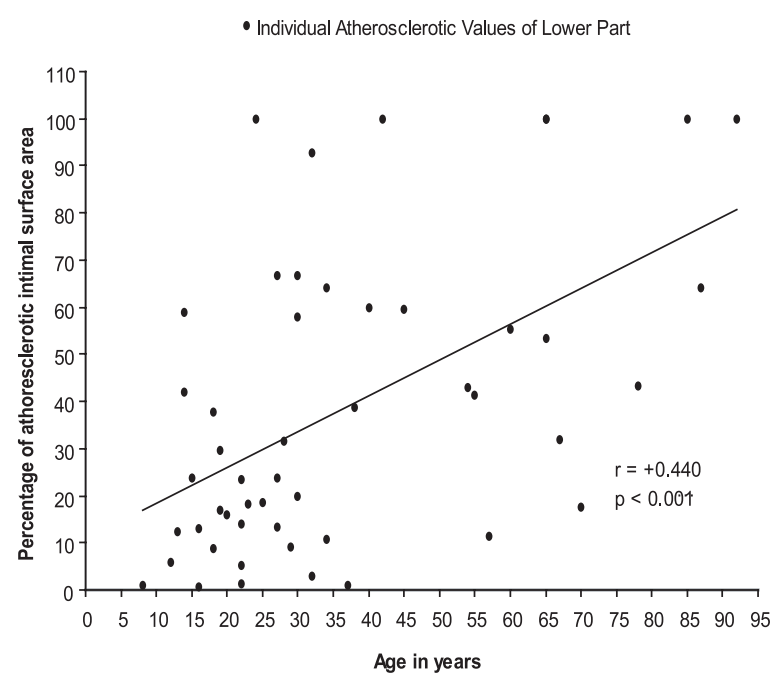

Fig..-2 Scatter diagram with correlation analysis showing significant positive correlation between the age of the cadaver and percentage of intimal surface affected by atherosclerosis in the lower part of the abdominal aorta.

\section{Discussion:}

A general trend of increasing percentage of lesion with increasing age has been showed in the results of the present study. When ranges of percentage involvement in different age groups were considered, it was found that the highest values were $100 \%$ in lower and higher age group and $92.64 \%$ in the middle age group. The lowest age at which atherosclerosis was found in the present study was 8 years. It was reported that, a study on whole aorta of 500 Indians from Agra, the earliest lesion being at the age of $2^{1 /}$ ${ }_{2}$ years $^{11}$. Another study on the infrarenal segment of aorta of 50 Bangladeshi males, observed that the earliest lesion being at the age of 7 years ${ }^{9}$. It was also demonstrated that, lesions were detected even at the age of 9 months in an American child ${ }^{10}$ (Holman et al., 1958). It has been well-documented that the presence of preliminary involvement (usually as fatty streaks) in the first two decades of life does not vary markedly with age, sex, race or environment ${ }^{12,11,13,14}$. 
In the present study, one sample from 14 years old boy showed $59.58 \%$ affected area. There was about $17 \%$ and $8.5 \%$ involvement in the infrarenal aortic segment of a 11 and a 12 years old boy respectively ${ }^{9}$. This rise is around puberty which has been attributed to the possible effect of hormonal changes during puberty ${ }^{10}$. In the present study, a very similer result was found as noted by the workers.

In the present study, $100 \%$ aortic segment involvement was found $5^{\text {th }}, 7^{\text {th }}, 9^{\text {th }}$ and $10^{\text {th }}$ decades of life. Very similar result was reported by ${ }^{9}$ that $6^{\text {th }}$ and $7^{\text {th }}$ decades of life, 7 men out of 9 , represented with 100 percent intimal involvement of infrarenal aortic segment. In the present study, the percentage area involved was shown significant positive correlation with age. Similarity was found in a study on infra renal segment of abdominal aorta in Bangladeshi males ${ }^{9}$.

\section{References:}

1. Schoen FJ Cotran RS. Blood vessels. In: Cotran RS, Kumar V, Collins T, editors. Robin's Pathologic Basis of Disease. $7^{\text {th }}$ ed. Philadelphia: WB Swanders Company, 2004; 516-25.

2. Libby P. Diseases of Blood Vessels. In: Isselbacher $\mathrm{KJ}$, Braunwald E, Wilson JD, Martin JB, Fauci AS, Kasper DL, editors, Harrison's principle of internal medicine. 15ed. New York: McGraw-Hill Inc, 2001; 1377- 88.

3. Basavaraju SR, Jones TD. Atherosclerotic risks from chemicals: Part1.Toxicological observations and mechanisms of atherosclerosis. Arch Environ Contam toxicol 1998; 35(1): 152-64.

4. Joseph L. Thematic reviews on the pathogenesis of atherosclerosis. J Lip Res 2004; 45(6): 991-2.

5. Ross R. Atherosclerosis-An inflammatory disease. N Eng J Med 1999; 340: 115-26.
6. Boon NA, Fox KAA. Cardiovascular disease. In: Edwards CRW, Bouchier IAD, Haslett C, editors. Davidsons principle and practice of medicine. $19^{\text {th }}$ ed. London: ELBS with Churchill Livingstone, 2002; 420-23.

7. Zarins $\mathrm{CK}, \mathrm{Xu} \mathrm{C}$, Glagov S. Atherosclerotic enlargement of the human abdominal aorta. Atherosclerosis 2001; 155(1): 157- 64.

8. Zhdanov VS, Sternby NH, Vikher AM, Galakhov IE. Development of atherosclerosis over a 25 year period : an epidemiological autopsy study in males of 11 towns. Int. J Cardiol 1999; 68(1): 95-106.

9. Begum S. Postmortem study of atherosclerosis in the abdominal aorta of Bangladeshi males [thesis].Dhaka: BSMMU; 1998.

10. Holman RL, McGill HC Jr, Strong JP, Gur JC. Techniques for studying atherosclerotic lesions. Lab Invest 1958a; 7: 42-7.

11. Mathur KS, Patney NL, Kumar V. Atherosclerosis in India: an autopsy study of aorta and the coronary, cerebral, renal and pulmonary arteries. Circulation 1961; 24: 6875.

12. Gore I, Robertson WB, Hirst AE, Hadley GG, Koseki Y. Geographic differences in the severity of aortic and coronary atherosclerosis in the United States, Jamaica, W.I., South India and Japan. Am J Pathol 1960; 36: 559- 73

13. McMillan GC. Development of arteriosclerosis. Am J Cardiol 1973; 31: 542-6.

14. Stray HC, Chandler AB, Dinsmore RE, Fuster V, Glagov S, Wissler RW. A definition of initial, fatty streak and intermediate lesions of atherosclerosis. Circulation 1994; 89: 246278. 